\title{
COVID-19: a Review of the Literature Regarding African American Patient Outcomes
}

\author{
Vincent E. Mangum ${ }^{1}[$
}

Accepted: 13 January 2021 / Published online: 26 January 2021

(C) The Author(s), under exclusive licence to Springer Science+Business Media, LLC part of Springer Nature 2021

\begin{abstract}
In December 2019, COVID-19 was detected in Wuhan, China, and declared a pandemic in March 2020. The Centers for Disease Control and Prevention (CDC) says it has been detected in nearly 200 countries and is an ongoing concern in the United States. Various reports provided anecdotal evidence that many ethnic minorities and specifically African Americans have become ill and died from COVID-19. Coincidentally, several states have provided data that at least initially corroborate the anecdotes. Narratives and descriptive data were compiled from medical and public health professionals to ascertain whether medical evidence supports the overrepresentation of state-level total infections and deaths of African Americans. The ramifications are critical for African Americans, non-medical professional, citizens, and also to the reduction and mitigation of the novel coronavirus as an American pandemic. The medical and health policy literature suggests that African Americans are burdened with a disproportionate share of persons contracting and dying due to COVID-19. Authors and witnesses believe that their occupation as essential workers, poverty, health access, government distrust, comorbidities, and Social Determinants of Health (SDH) are important factors for further research. For these reasons, federal funding of a rigorous and robust national public health study of COVID19 and African Americans is highly recommended and the next logical step to develop mitigation strategies that reduce infection, mortality, and disparate medical outcomes.
\end{abstract}

Keywords COVID-19 · African Americans · Comorbidities · State infection and mortality rates $\cdot$ Social determinants of health

JEL $\mathrm{H} 51 \cdot \mathrm{I} 14 \cdot \mathrm{I} 30$

Vincent E. Mangum

vmangum@atlm.edu

1 School of Business and Technology, Atlanta Metropolitan State College, 1630 Metropolitan Parkway, SW, Atlanta, GA 30310, USA 


\section{Introduction}

\section{Background}

In late December 2019, the novel coronavirus was first detected in Wuhan, China, and developed into an international outbreak with infection and mortality rates that have been compared with the influenza pandemic of 1918 (Azar et al., 2020; Barro et al., 2020). According to the Centers for Disease Control and Prevention (CDC) and the World Health Organization (WHO), COVID-19 has now been detected in nearly 200 countries and is an ongoing concern in the United States (U.S.).

Various reports provided anecdotal evidence that many ethnic minorities and, specifically, African Americans have been ill and died from COVID-19. Coincidentally, states such as Michigan and Louisiana have provided data points that at least initially corroborate the anecdotes. Gaglioti et al. (2020) report that during March 2020 in Georgia, 80\% of all hospitalizations reported were non-Hispanic African. Gaglioti et al. (2020) also found that in Georgia the COVID-19 infection rate was significantly and positively correlated with the African American proportion of county population. Examination of disparate medical outcomes may acknowledge an emergent need for a national public health study of causal factors, develop solutions to immediately address outcomes and healthcare disparities across ethnicity, and reveal strategies that may reduce African American COVID-19 infection and mortality.

Dorn et al. (2020) report that COVID-19 does not affect everyone equally. In the U.S., it is exposing inequities in the health system and confirming existing disparities within New York City and other urban centers.

Across the country, deaths due to COVID-19 are disproportionately high among African Americans compared with the population overall. In Chicago, IL, African Americans' mortality is six times the rate of white residents' mortality (Reyes et al., 2020). In Milwaukee, WI, three quarters of all COVID-19-related deaths were African American, and in St Louis, MO, all but three people who have died as a result of COVID-19 were African American (Dorn et al., 2020).

Pre-existing racial and health inequalities already present in U.S. society are being exacerbated by the pandemic. Sharrelle Barber, Ph.D., of Drexel University stated, "African Americans, Latino and immigrant communities, Native Americans are going to bear the disproportionate brunt of the reckless actions of a government that did not take the proper precautions to mitigate the spread of this disease and that's going to be overlaid on top of the existing racial inequalities" (Dorn et al., 2020, p. 1). Various policies may include the partial lockdown of schools, universities, businesses, and where the diffusion parameters are stratified by age and individual covariates (Alvarez et al., 2020).

The review of the initial early available literature has discussed several possible factors that may be a basis for the over-representation of African Americans in the proportion of the COVID-19 infected and deaths. Those factors include occupation, poverty, geography, health access, government distrust, comorbidities, and Social Determinants of Health (SDH). 
This non-medical research article is a commentary narrative literature review that synthesized available medical literature regarding COVID-19 and African Americans as far as June 2020 (Table 1).

This study expeditiously synthesized limited public health literature on COVID19 and African American outcomes by exploring how medical researchers conceptualize and incorporate race and ethnicity in their conclusions regarding COVID19 health disparities (Lee, 2008). Medical researchers' findings could be utilized to develop strategies in the short-term to reduce the excessive and growing pandemicspecific health disparities. Second, medical and epidemiological evidence is compiled, elucidating a literary consensus emphasizing the development of a national public health study on this pandemic disparity. The issue of race and ethnicity in medical research is particularly important now, given the rise in attention to health disparities in this American pandemic. The issue has become political with many that have taken sides and supported or declined mitigation strategies based on partisan affiliation.

\section{Method and Discussion}

This research study design, due to this emergent unexpected pandemic outcome, implemented a search expeditiously for peer-reviewed and news-oriented literature regarding "African Americans and COVID-19." This technique samples considerable and representative literature on any "hot" or pressing and current topics of interest (Fink, 2019). Given the nature of an active pandemic, published peer-reviewed journal articles are quite limited. Waiting for article publishing and release time does not elevate this issue to the plateau nor communicate the urgency it deserves in the short term.

While all articles included the search terms, pertinent and valuable information was gleaned from the medical opinions exercised freely by the authors. All articles found the need for additional research due to the prevalence of nationwide anecdotes on this issue that find a correlation with proportion of infection and mortality running higher than the African American portion of state populations.

Authors' thoughts and opinions on the sources of disproportionate infection and mortality rates were sorted into the following list: historical and current systemic American racist practices, occupational status as "essential workers," poverty, healthcare access, comorbidities, and social conditions as the determinants of health.

Table 1 Sources of available medical literature regarding COVID-19 and African Americans

\begin{tabular}{ll}
\hline Sources for the Commentary Review & Article Count \\
\hline news.google.com & 53 \\
TheLancet.com & 32 \\
CDC.gov & 16 \\
The Morehouse School of Medicine & 1 \\
JSU School of Public Health & 1 \\
\hline
\end{tabular}


Various articles mentioned racist practices as an antecedent of healthcare inequality; however, an overwhelming majority stated that comorbidities are the root cause connected to the proportion of deaths.

\section{African American COVID-19 Infection Production Mechanism}

The medical outcomes extolled by various healthcare professionals were mechanistically produced from conditions that are a component of and existed apart from this pandemic. Worker personal health condition and socioeconomic circumstances are central factors that have produced disparate outcomes. Various public health literatures share anecdotes of African American lifestyle habits and wanting cultural diet. Residential locations are a contributing factor shown by the high proportion of African Americans living in food deserts (communities without grocery stores selling fresh produce).

Thornton's (2002) model may be useful in estimating and explaining American health disparities produced in this pandemic. Thornton stated, "the most important factors that influence mortality are related to socioeconomic status and lifestyle. The results suggest that a health care policy which focuses primarily on the provision of medical care services and ignores larger economic and social considerations may do little to benefit the health for those experiencing poverty and limited access" (Thornton, 2002, pg. 2).

Due to incomplete science and almost daily information on the medical impact of the Coronavirus, additional factors may be contributing to the increased infection and mortality. Racist practices and African American distrust in government medical services could lower the likelihood of them seeking medical care earlier that would enhance their likelihood of survival. For example, physicians and public health experts suggest that healthcare access and fewer doctors' visits contribute to the higher level of comorbidities in the African American community increasing the possibility of a higher African American Coronavirus mortality (Shahbazi, 2020).

The comorbid-related literature suggests there may be some interaction with personal pre-existing health conditions and COVID-19 infection and mortality outcomes. The SDH literature reports similarly that social conditions interact with disease and may be causal on medical outcomes as well, e.g., living in urban or rural low-income communities with food insecurity and high poverty, unemployment, and crime.

African Americans' share of those who have died from COVID-19 nationally is nearly double (1.8 times higher than) their share of the U.S. population (CDC, 2020; Millett et al., 2020). The ratios are even higher in some states: in California, Kansas, and Wisconsin; the rate of African American deaths is more than four times as high as their share of the population in those states (Azar et al., 2020; Meepagala \& Romer, 2020). Understanding this process through a national public health investigation can both assist in the reduction of unsatisfactory pandemic outcomes and mitigate systemic disparities in American healthcare.

Higher mortality from COVID-19 has been locally documented in African American populations from New Orleans, LA; Chicago, IL; Milwaukee, WI; Detroit, MI; and even rural Albany, GA. For example, $70 \%$ of the people who have died from coronavirus 
in Louisiana are African, a striking disparity for a state where African Americans make up only $32 \%$ of the population (Deslatte, 2020). Similarly, African Americans comprise $14 \%$ of the population in Michigan, but represent $40 \%$ of COVID-19 deaths (Dyer, 2020).

\section{Essential Workers and Poverty}

African Americans and many people of color are more likely to provide high-risk essential services, including low-wage jobs that cannot be done remotely, and to have fewer financial resources to draw on in the event of health problems or economic disruption. Market and income needs place the family in a perilous position when the essential worker returns home (Chaney \& Morath, 2020; Gould \& Wilson, 2020).

Labor discrimination is a factor in the accrual of African Americans in low-wage industries that are labor intensive during the pandemic and that have become "essential" work due to the societal and economic needs. According to Center for Economic and Policy Research (CEPR), three-in-ten African workers work in six frontline industry groups. Twenty-six percent of all public transit workers are African American. In the building cleaning services industry, nearly $53 \%$ of workers are African and Hispanic, $65 \%$ achieved only a high school or less educational attainment, and almost $16 \%$ live below poverty. Industry groups deemed essential include health care; grocery, convenience, and drug stores; childcare and social services; trucking, warehouse, and postal services; public transit; and building cleaning services (Rho et al., 2020).

\section{Distrust in Government and Medical Institutions}

Price (2012) defined government trust as a form of social capital, whereby trust is the benefit associated with the acceptance of decisions made by a representative agent of government regarding public goods to the benefit of all members of the community.

African Americans have experienced various unethical misdeeds at the hands of government and medical personnel. Some historical travails include violent interactions with police (considered agents of local government) and the Eugenic Sterilization in North Carolina from 1958 to 1968. Racist eugenic policies were devised based on a rationale developed by Irving Fisher that categorized African Americans as degenerate, a drag on economic growth and therefore deserving of being sterilized, unable to reproduce. Eugenic policy based on Fisher's rationale advocated eugenic boards to be developed in every state to end the breeding capacity of all those deemed to be unfit to be productive members of society (Kennedy et al., 2007; Price \& Darity, 2010).

Pertinent to the current pandemic with potential impact for future vaccine inoculation is The Tuskegee Experiment from 1932 to 1972, which created distrust of medicine by ostensibly allowing African Americans to die untreated. Historical misdeeds and maltreatment have created a measurable distrust that may slow testing and hospitalization of African Americans during this COVID-19 crisis (Price, 2012; Shahbazi, 2020). 


\section{Racism and Healthcare Access}

Historically, in the U.S., African Americans have disproportionately battled the scourge of deprivation due to poverty as a result of racist employment and banking practices when compared with other ethnicities (Price et al., 2008). These systemic practices have culminated in an economic environment that limits healthcare affordability and access and that lowers rates of income, homeownership, business ownership, and wealth attainment (Mangum, 2020). Fourteen mostly southern states have not accepted the Affordable Care Act Medicaid expansion (designed to provide healthcare to persons with a limited income), leaving millions of the poorest and sickest Americans without access to health care. An additional problem is "The added effect of leaving many regional and local hospitals across the U.S. in danger of closing because of the cost of providing medical care and a high proportion of uninsured people" (Dorn et al., 2020, p. 2).

Slightly more than $12 \%$ (40.3 million) of the U.S. population is African American, according to the Census Resident Population Estimates 2019. Compared with white Americans, they are less likely to have employment-based health insurance, more likely to be covered by Medicaid or other publicly funded insurance, and twice as likely to be uninsured, even though eight of 10 are in working families. A disproportionate percentage of African Americans work in jobs that do not provide health insurance. Many African Americans, especially those who are poor and those working without health care benefits, are less likely than white Americans to have a usual source of health care (Copeland, 2005; Artiga et al., 2020).

\section{Comorbidities}

The underlying comorbid conditions, such as cardiovascular disease, hypertension, diabetes, obesity, and asthma, are reflections of structural societal inequities and not simply poor lifestyle choices that possibly have led to higher COVID-19 African American mortality, in both urban and rural environments. The top 3 underlying conditions among COVID-19 deaths in Louisiana are hypertension (59.76\%), diabetes (38.10\%), and chronic kidney disease (22.50\%) (Bornstein et al., 2020; Deslatte, 2020; Ferdinand \& Nasser, 2020).

Patients with diabetes, often associated with obesity and hypertension, may be more susceptible to an inflammatory storm eventually leading to rapid progression and adverse prognosis of COVID-19. Thus, effective control of these metabolic parameters may represent an approach to prevent and ameliorate the acute effects of COVID-19.

\section{Social Conditions as the Determinants of Health}

Kosa et al. (1969) completed some of the earliest research connecting personal living and social conditions to healthcare outcomes. The prolonged negative impact of racism, discrimination, poverty, substandard housing and neighborhood conditions, insurance status, and insufficient availability of and access to quality health care 
have all been linked to poor health outcomes among African Americans (Levine et al., 2014).

Ahmed et al. (2020) observed the correlation between poverty and heart failure outcomes, with lower socioeconomic status linked to increased COVID-related hospitalization and mortality.

The communities where many African people reside are in poor areas characterized by high housing density, high crime rates, and poor access to healthy foods. Low socioeconomic status alone is a risk factor for total mortality, independent of any other risk factors. These social determinants of health must be considered, including known cardiovascular risk factors which put minority communities at greater risk for disease, not just for cardiovascular diseases but now for COVID-19 mortality (Yancy, 2020).

\section{Summary}

Twenty-two percent of U.S. counties are majority African American, yet African Americans disproportionately accounted for 52\% of COVID-19 diagnoses and 58\% of COVID-19 deaths, nationally (Millett et al., 2020). County-level comparisons can both inform COVID-19 responses and identify epidemic hot spots. Social conditions, structural racism, and other factors elevate risk for COVID-19 diagnoses and deaths in African communities (Millett et al., 2020).

Given the known risk factors for COVID-19 complications, the confluence of hypertension, diabetes, obesity, and the higher prevalence of cardiovascular disease among African persons may be driving these early outcomes. Data fully adjusted for comorbidities have not been reported, but it is likely that some, if not most, of these differences in disease rates and outcomes will be explained by concomitant comorbidities (Mona et al., 2020). A sixfold increase in the rate of death for African Americans due to a now ubiquitous virus is unconscionable and demands a rigorous national study (Yancy, 2020).

\section{Limitations of the Research Design}

A major limitation to this literature review is the ongoing and evolving science and impact of the novel Coronavirus. This research has captured the prevailing science available as far as June 2020.

Going beyond a single subject database is important not only for ensuring that as many relevant studies as possible are identified but also to minimize selection bias for those that are found. Time and budget constraints require the review author to balance the thoroughness of the search with efficiency in use of time and resources, and the best way of achieving this balance is to be aware of and to try to minimize publication bias.

However, these constraints and deadlines have implications and may impact this literature review by the following: (1) currently, the science of the Coronavirus is incomplete; (2) near daily development of new information regarding the 
Coronavirus; (2) the full medical impact of the Coronavirus is unknown due to its novelty; (3) the ongoing nature of this pandemic without an available vaccine; and (4) new data and literature produced daily that may cast initial concerns regarding African American outcomes as coincidental. This literature review limitations provide the basis for its purpose while also presenting the opportunity and necessity for future updates to this research.

\section{Conclusions, Policy Implications, and Recommendations}

Ethnicity could interplay with virus spread through cultural, behavioral, and societal differences including lower socioeconomic status, health-seeking behavior, and intergenerational cohabitation.

Disentangling the relative importance of these factors requires both prospective studies, focusing on quantifying absolute risks and outcomes, and qualitative studies of behaviors and responses to pandemic control policies. If ethnicity is found to be associated with adverse COVID-19 outcomes, this must directly, and urgently, inform public health mitigation strategies globally.

It is imperative for policy makers to urgently ensure that ethnicity forms part of a minimum dataset. More importantly, ethnicity-disaggregated data must occur to permit identification of potential outcome risk factors through adjustment for recognized confounders.

Ultimately, to limit future unnecessary loss of life, the COVID-19 crisis must be seen as an opportunity to fully address COVID-19 disparities and the underlying comorbid and SDH factors (Ferdinand \& Nasser, 2020). Nationally, data resources and studies on this issue are sparse due to the novelty of the Coronavirus, evolving nature of this pandemic, inconsistencies in reporting COVID-19 infections, and deaths across ethnicity, further exacerbating potential disparities that remain unknown.

Supporting evidence has acknowledged an emergent need for a national public health study of causal factors and solutions to immediately address healthcare disparities and outcomes across ethnicity and reveal specific strategies that may reduce African American COVID-19 mortality. Louisiana and Michigan recently formed task forces to address COVID-19 health disparities.

It is highly recommended that a national organization such as either or both of the Centers for Disease Control and Prevention and the National Institutes of Health mobilize to action the necessary talent and resources to resolve this crisis in disparate COVID-19 healthcare outcomes enveloping the African American community. Gaglioti et al. (2020) state that their study shows the need for resources to collect and report accurate infection data and also where resources are most needed. Deploying federal resources exhibits prudent action that protects racial and ethnic minorities who are suffering, representing America's most vulnerable that do not have a safety net and are the unprotected (Laurencin \& McClinton, 2020). 


\section{References}

Ahmed, F., Ahmed, N.E., Pissarides, C., \& Stiglitz, J. Why inequality could spread COVID-19. Lancet Public Health. 2020. https://doi.org/10.1016/S2468-2667(20)30085-2.

Alvarez, F., Argente, D., \& Lippi, F. A Simple Planning Problem for COVID-19 Lockdown. The Becker Friedman Institute. 2020 Working Paper No. 2020-34.

Artiga, S., Orgera, K., \& Damico, A. Changes in Health Coverage by Race and Ethnicity since the ACA, 2010-2018 [Internet]. San Francisco (CA): Kaiser Family Foundation; 2020 March. Available from: http://files.kff.org/attachment/Issue-Brief-Changes-in-Health-Coverage-by-Race-and-Ethnicitysince-the-ACA-2010-2018.pdf

Azar, K., et al. (2020). Disparities in outcomes among COVID-19 patients in a large health care system in California. Journal of Health Affairs., 39(7), 1-8. https://doi.org/10.1377/hlthaff.2020.00598.

Barro, R.J., Ursua, J., \& Weng, J. "The Coronavirus and the Great Influenza pandemic-lessons from the 'Spanish Flu' for the Coronavirus's potential effects on mortality and economic activity," CESifo 2020 Working Paper No. 8166.

Bornstein, S. R., et al. (2020). Endocrine and metabolic link to coronavirus infection. Nat Rev Endocrinol. https://doi.org/10.1038/s41574-020-0353-9.

Centers for Disease Control and Prevention. Coronavirus (COVID-19) [Internet]. Atlanta (GA): CDC; 2020 May 12. Available from: https://www.cdc.gov/coronavirus/2019-ncov/index.html

Chaney, S., \& Morath, E. "Record 6.6 million Americans sought Unemployment Benefits Last Week", Wall Street Journal. Accessed 3 April 2020.

Copeland, V. C. (2005). African Americans: disparities in health care access and utilization. Journal of Health and Social Work, 30(3), 265-270.

Deslatte, M. Louisiana data: virus hits Africans, people with hypertension. US News World Report. Published April 7, 2020. Accessed 12 April 2020.

Dorn, A. V., Cooney, R. E., \& Sabin, M. L. (2020). COVID-19 exacerbating inequalities in the US. Lancet, 395(10232), 1243-1244. https://doi.org/10.1016/S0140-6736(20)30893-X.

Dyer, O. (2020). Covid-19: African people and other minorities are hardest hit in US. BMJ, 369, m1483. https://doi.org/10.1136/bmj.m1483.

Ferdinand, K. C., \& Nasser, S. A. (2020). African American COVID-19 mortality: a sentinel event. Journal of the American College of Cardiology. https://doi.org/10.1016/j.jacc.2020.04.040.

Fink, A. (2019). Conducting Research Literature Reviews: From Internet to the Paper (5th ed.). London: Sage Publications.

Gaglioti, et al. County-level proportion of non-Hispanic African population is associated with increased county confirmed COVID-19 case rates after accounting for poverty, insurance status, and population density. morehouse school of medicine, National Center for Primary Care, 2020 White Paper.

Gould, E., \& Wilson, V. African workers face two of the most lethal preexisting conditions for coronavirus-racism and economic inequality. Economic Policy Institute, June 2020.

Kennedy, B. R., Mathis, C. C., \& Woods, A. K. (2007). African Americans and their distrust of the healthcare system: healthcare for diverse populations. Journal of Cultural Diversity, 14(2), 56-60.

Kosa, J., et al. (1969). Poverty and health: a sociological analysis. Cambridge, MA: Harvard University Press.

Laurencin, C. T., \& McClinton, A. (2020). The COVID-19 pandemic: a call to action to identify and address racial and ethnic disparities. Journal of Racial and Ethnic Health Disparities. https://doi. org/10.1007/s40615-020-00756-0.

Lee, C. (2008). "Race"” and "ethnicity" in biomedical research: how do scientists construct and explain differences in health? Social Science \& Medicine, 68, 1183-1190.

Levine, R. S., Kilbourne, B. A., Rust, G. S., Langston, M. A., Husaini, B. A., Gittner, L. S., et al. (2014). Social determinants and the classification of disease: descriptive epidemiology of selected socially mediated disease constellations. PLOS ONE, 9(11), e110271. https://doi.org/10.1371/journal. pone.0110271.eCollection2014.PubMedPMID:25372286;PubMedCentralPMCID:PMC4220931.

Mangum, V. E. (2020). What does political economy tell us about the dearth of African entrepreneurs? The American Economist, 65(1), 131-143.

Meepagala, S., \& Romer, C. "Mapping Racial and Ethnic Differences with COVID-19" (interactive data tool). Center for Global Data. Accessed 29 May 2020. 
Millett, G. A., Jones, A. T., Benkeser, D., Baral, S., Mercer, L., Beyrer, C., et al. (2020). Assessing differential impacts of COVID-19 on African communities. Annals of Epidemiology. https://doi. org/10.1016/j.annepidem.2020.05.003.

Mona, N., Fouad, M. D., MPH, John Ruffin, PhD, Selwyn M. Vickers, MD, FACS , COVID-19 is out of proportion in African Americans. This will come as no surprise..., The American Journal of Medicine 2020, https://doi.org/10.1016/j.amjmed.2020.04.008

Price, G. N. (2012). Race, trust in government, and self-employment. The American Economist, 57(2), 171-187. https://doi.org/10.1177/056943451205700203.

Price, G. N., \& Darity, W. A., Jr. (2010). The economics of race and eugenic sterilization in North Carolina: 1958-1968. Economics and Human Biology, 8(2), 261-272. https://doi.org/10.1016/j. ehb.2010.01.002.

Price, G. N., Darity, W. A., Jr., \& Headen, A. E., Jr. (2008). Does the stigma of slavery explain the maltreatment of Africans by whites?: the case of lynchings. The Journal of Socio-Economics, 37(1), $167-193$.

Reyes, C., Husain, N., Gutowski, C., St. Clair, S., \& Pratt, G. Chicago's coronavirus disparity: African Chicagoans are dying at nearly six times the rate of white residents, data show. Chicago Tribune [serial on the Internet]. 2020 Apr 7 Available from: https://www.chicagotribune.com/ coronavirus/ct-coronavirus-chicago-coronavirus-deaths-demographics-lightfoot-2020040677nlylhiavgjzb2wa4ckivh7mu-story.html.

Rho, H. J., Brown, H., \& Fremstad, S. A basic demographic profile of workers in frontline industries. Center for Economic and Policy Research, April 2020.

Shahbazi, M. JSU's Shahbazi: Africans hit hardest than others by COVID-19 can blame "structural racism". Jackson State University, School of Public Health, June 172020.

Thornton, J. (2002). Estimating a health production function for the US: some new evidence. Applied Economics, 34(1), 59-62. https://doi.org/10.1080/00036840010025650.

Yancy, C. W. COVID-19 and African Americans. JAMA. Published online April 6, 2020. https://doi. org/10.1001/jama.2020.6548.

Publisher's Note Springer Nature remains neutral with regard to jurisdictional claims in published maps and institutional affiliations. 